\title{
How is the COVID-19 Pandemic Affecting Global Supply Chains, Logistics, and Transportation?
}

Author(s): Oh Kyoung Kwon

Source: Journal of International Logistics and Trade 2020; 18(3):107-111

Published by: Jungseok Research Institute of International Logistics and Trade, Inha University

DOI: https://doi.org/10.24006/jilt.2020.18.3.107

The Journal of International Logistics and Trade is an official journal published by Jungseok Research Institute of International Logistics and Trade, Inha University, Korea. JILT welcomes manuscripts that advance the practice and science of logistics, trade, and other related fields.

Frequency: Quarterly (March, June, September, December)

Stable URL: https://www.ejilt.org

The Jungseok Research Institute of International Logistics and Trade is a specialized academic research institute representing Inha University and the Inha Foundation in Korea. The institute aims to become a representative institute in Northeast Asia in the research of logistics and trade.

Stable URL: https://jrieng.inha.ac.kr

(C) Copyright. Jungseok Research Institute of International Logistics and Trade.

This is an Open-Access article distributed under the terms of the Creative Commons Attribution NonCommercial License (http://creativecommons.org/licenses/by-nc/4.0/) which permits unrestricted noncommercial use, distribution, and reproduction in any medium, provided the original work is properly cited 


\title{
Journal of International Logistics and Trade
}

J. Int. Logist. Trade, 2020, Vol. 18, No. 3, 107-111

pISSN : 1738-2122 eISSN : 2508-7592

https://doi.org/10.24006/jilt.2020.18.3.107

https://www.ejilt.org

\section{EDITORIAL}

\section{How is the COVID-19 Pandemic Affecting Global Supply Chains, Logistics, and Transportation?}

\author{
Oh Kyoung Kwon* \\ Asia Pacific School of Logistics, Inha University, Incheon, Korea
}

Received $\quad$ September 19, 2020
Revised $\quad$ September 22, 2020
Accepted September 25, 2020

*Corresponding author: Oh Kyoung Kwon
Asia Pacific School of Logistics, Inha
University, Incheon, Korea
Tel: +82-32-860-7765
E-mail: scm@inha.ac.kr

\begin{abstract}
This editorial establishes the broader context for debating how the COVID-19 pandemic is affecting the global supply chains, logistics, and transportation networks in the world. The COVID-19 pandemic is an unknown-unknown risk whereby the probability of its occurrence and the possible consequences of a risk event cannot be foreseen. Furthermore, the characteristics of COVID-19 differentiate it from previous disasters in terms of the geographic scope of the impact, and the supply- and demand-side impacts, and are making relevant research challenging. In this special issue, the interwoven relationships between the COVID-19 pandemic and the challenges facing global supply chains, logistics, and transportation are discussed, along with a literature review. Selected papers on air transportation networks, emergency logistics, and digital trade are theoretically and empirically probed.
\end{abstract}

Keywords COVID-19, Global value chains, Supply chain risk, Transportation networks

\section{Introduction}

At the end of December 2019, China reported several cases of an acute respiratory infection in Wuhan City, Hubei Province, China. The World Health Organization (WHO) named the previously unknown virus severe acute respiratory syndrome coronavirus 2 (SARS-CoV-2) and named the disease caused by the virus coronavirus disease (COVID-19) (WHO 2020). Since its outbreak, COVID-19 has been rapidly and extensively spreading around the globe, totaling about 30 million confirmed cases with 937,391 deaths as of 17 September 2020 according to the WHO.

The COVID-19 pandemic is threatening the health of humanity and is having a serious impact on the global economy, which had been gradually gaining momentum in its recovery from the slow growth phase that continued after the global financial crisis in 2008. It has also caused disruptions in global production lines, supply chain, international trade, and the maritime and aviation network in the world. Such disruptions are incomparable to the past impacts caused by, among other things, terrorist attacks, natural disasters (earthquakes, typhoons, and tsunamis), and epidemics (SARS and MERS).

Today, the world is closely connected via high-speed internet, and the development of high-speed transportation allows people and goods to move more freely and economically than in any previous era. On the one hand, 'connectivity' and 'mobility' have promoted globalization and have driven the growth of the global economy. On the other hand, they caused COVID-19 to quickly spread, nationally and internationally.

With trade liberalization and the spread of offshoring over the last several decades, world trade and production have been structured around global value chains (GVCs). Currently, about 70\% of world trade is related to GVCs (OECD 2020). The global economy, in which almost all countries and industries are closely connected, forward and backward through GVCs and international transportation networks, is facing an unprecedented crisis triggered by 'connectivity' and 'mobility' disruptions from the COVID-19 pandemic. The WTO (2020) estimates that the volume of world merchandise trade in 2020 will fall by somewhere between an optimistic 13 and a pessimistic 32 percent. Sherman (2020) reported that $94 \%$ of the companies listed in the Fortune 1000 are seeing supply chain disruptions from COVID-19.

It is most desirable to predict and prevent risk in advance, but if this is not possible, it is necessary to minimize disruptions and losses due to risks and to further analyze the causes and impacts of the risks to prepare for future crises. The COVID-19 pandemic can be classified as an unknown-unknown risk whereby the probability of occurrence and the possible consequences 
of a risk event cannot be foreseen. Compared to other previous disasters, COVID-19 differentiates itself in terms of the geographic scope of the impact, and the supply- and demand-side impacts. While most natural disasters have a limited geographic scope, COVID-19 is a global disaster. While previous natural disasters mainly affected the supply side and the financial crisis in 2008 largely affected the demand side of the market, COVID-19 is disrupting both the supply and demand. These differences pose new challenges to analyzing the impact of the COVID-19 pandemic.

A recent OECD report suggested that the impact of COVID-19 appears in four GVC channels: direct impacts, indirect impacts, demand impacts, and policy risks (OECD 2020). There is an indirect supply chain impact when production at one location requires input from another location where a disaster has occurred. Disruption in international transportation networks also affects the global supply chain that relies on transportation. Such a "ripple effect" makes it difficult to analyze the impact of COVID-19.

Furthermore, the crisis due to COVID-19 is still in progress, and data and cases for analyzing and evaluating its impact are scarce. Nevertheless, research on the social and economic impacts of COVID-19 has been actively attempted recently. Queiroz et al. (2020) performed a systematic analysis of the impact of epidemic outbreaks on supply chains based on a structured literature review. They proposed a framework for operation and supply chain management during the COVID-19 pandemic based on analysis. Golan et al. (2020) provided a comprehensive literature review on supply chain resilience in the context of the COVID-19 pandemic.

McKibbin and Fernando (2020) estimated the macroeconomic impacts of COVID-19 under seven different scenarios using a general equilibrium model. Ivanov (2020) examined the impacts of COVID-19 on global supply chains through a simulationbased approach. Loske (2020) attempted to analyze the impact of COVID-19 on transport volume and supply dynamics using empirical data on German retail food logistics. He looked at the relationship between different product line transport volumes and COVID-19 cases. The impact of COVID-19 on international transportation networks and industries is not being actively analyzed mainly due to the limited availability of relevant data and cases. Meanwhile, IATA (2020) reported that international passenger traffic in June 2020 shrank by 96.8\% compared to June 2019, while domestic traffic fell 67.6\%. It also projected that global air passenger traffic will not return to pre-COVID-19 levels until 2024.

This special issue is designed as an early attempt in a series of studies to explore the impact of the COVID-19 pandemic on global supply chains, logistics, and transportation, and to learn lessons from this unprecedented disaster.

\section{Impacts of the COVID-19 on the global supply chains, logistics, and transportation}

The three papers for this special issue were collected from the call for papers on the journal website and in one e-workshop: JRI e-Workshop on International Logistics and Trade in the Post-COVID-19 World on 25 August 2020.

The first paper, "Dissection of a singularity: The impact of COVID-19 on aviation," by Xiaoqian Sun, Sebastian Wandelt, and Anming Zhang investigates the impact of COVID-19 on the global air transportation network through a complex network approach. Air transportation networks are configured into three different levels: the worldwide airport network, the intercountry air transportation network, and domestic airport networks. In this study, the data were collected from Flightradar24, which provides real-time information on thousands of aircraft around the world. The dataset includes 150 airlines from 2,751 airports over 152 days, from 19 December 2019, to 15 May 2020. To effectively analyze the spatial-temporal impacts of COVID-19, all flights were grouped by day into 24-hour intervals, yielding one network per day.

The analysis showed that the number of served origin-destination (OD) pairs, and the number of active aircraft, largely dropped to about one-third within about two weeks from the middle of March. It also indicated that the aviation industry showed a full-fledged reaction after about two months of the pandemic. The distance between served OD pairs and the aircraft efficiency were also examined, assuming certain limitations. To investigate the temporal changes in aviation network properties, six network metrics (degree, betweenness, closeness, clustering coefficient, assortativity, and communities) were computed at both airport and country levels. The authors attempted to identify the critical nodes in the world airport network by analyzing the node centralities before and after the pandemic.

Domestic airport networks were analyzed to see how air transportation has been affected by the pandemic within specific countries. Australia, China, Europe, and the United States were selected for comparison. The analysis showed that the connection density between European airports was most affected by the pandemic, compared to the United States and China. Finally, the relationships between flight frequency and the number of infected cases in 12 countries were examined. The authors diagnosed that, although further analysis is needed to clarify conclusions, most countries did not make timely flight reductions, which missed an opportunity to stop the spread of infection. 
Sun et al. (in press) contributes to expanding the air transportation literature by performing complex network analyses to examine the impact of large-scale disaster using the big-data source of the world aviation industry. As the authors mentioned in their conclusion, they expect to gain more insights by analyzing weighted network metrics that reflect link weights (Chung et al. 2020; Kim and Yoon 2019; Sun et al. 2017) such as the number of passengers and the available seats. Furthermore, more useful lessons could be obtained by exploring the relationships between network properties and exogenous variables such as policies on travel restrictions and border closures.

The second paper, "Implications of a Pandemic Outbreak Risk: A Discussion on China's Emergency Logistics in the era of COVID-19,” by Yui-yip Lau, Zhang Jiamian, A.K.Y., Ng, and Roozbeh Panahi attempts to identify the critical success factors for China's emergency logistics systems through the analysis of focus group interview data.

The authors were motivated to study the topic by pointing out that emergency logistics related to the epidemic were overlooked compared with other types of disasters. First, a literature review was conducted to identify the key factors required for the establishment and operation of an emergency logistics system. Secondly, they examined whether the emergency logistics system developed since the SARS outbreak in 2003 worked properly during the current COVD-19 pandemic. Third, they further investigate key success factors for emergency logistics in China by using the focus group interview method. Their study identified demand forecasting and planning, inventory management, location and distribution network, and systematic information management as the key government roles for successful emergency logistics operations in China. Given the pandemic, during which large-scale surveys are difficult to undertake, focus group interviews appear to be a useful alternative.

Lau et al. (in press) contribute to the emergency logistics literature through identification of key elements and success factors for emergency logistics systems in connection with China's COVID-19 pandemic. As the authors mention in their conclusion, more comprehensive data collection is recommended for further study in order to draw more convincing conclusions.

The third paper, "Issues of Digital Trade Rules and Implications for Korea in the post COVID-19 World," by Jungran Cho, Byunghee Ahn, Kyoungseo Hong, and Inkyo Cheong explores the institutional aspects of cross-border e-commerce (the socalled digital trade), which is expected to play a more important role in the post COVID-19 economy.

First, reviewing the existing literature, Cho et al. (in press) suggest that e-commerce will grow significantly after the COVID19 pandemic. Secondly, the recent trends in regulations and guidelines for digital trade by international organizations such as the WTO, the OECD, and APEC are summarized. The authors also emphasize that the articles or chapters about e-commerce have largely increased in most trade agreements. Third, the authors summarize the key issues in WTO digital trade regulations and the core digital trade policies of major countries. Finally, the current efforts and challenges of the Korean government to promote digital trade are discussed. In their conclusion, the authors point out that Korea lags developed countries in terms of preparing the institutional measures for digital trade. This paper contributes to identifying key institutional issues to mitigate barriers against digital trade, which are expected to grow significantly after the COVID-19 pandemic.

\section{Concluding remarks and suggestions}

Some of the reasons that make it difficult to analyze the impact of the COVID-19 pandemic on global supply chains, logistics, and transportation can be summarized as follows. First, it is an unknown-unknown risk, in that both the probability of occurrence and the consequences cannot be foreseen. Secondly, it is a global risk, because the impacts appear around the world. Third, there is a ripple effect on GVCs. A production disruption due to COVID-19 in one region has a ripple effect not only in that region but also in many other regions of the world connected backward and forward through the global value chains. Furthermore, the pandemic is disrupting both supply and demand in the markets. Lastly, the COVID-19 crisis is ongoing, with very limited data and cases to analyze the impact.

Despite the above constraints, research on the impact of the COVID-19 pandemic has been attempted recently, as outlined by the literature review in the introduction. This special issue is designed to explore the impact of the COVID-19 pandemic on global supply chains, logistics, and transportation, and to learn lessons from it.

Sun et al. (in press) provided meaningful insights regarding the impact of COVID-19 on the air transportation network. Their analysis showed that the number of served OD pairs, and the number of active aircraft, dropped to about one-third of normal starting from the middle of March 2020. It also showed that the aviation industry made a full-fledged response about two months after the pandemic outbreak. The authors diagnosed most countries as not making timely polices to reduce flights, concluded that they may have missed an opportunity to stop the spread of the epidemic.

An important factor that made such a timely analysis possible is the database accumulated by the aviation industry over decades. In the air and maritime transportation industry, thanks to advanced data collection technologies, near real-time data 
on the movement of passengers, cargo, and equipment can be obtained economically. Such a big-data capability will enable the timely assessment of events or disasters, but will also play an important role in detecting abnormal conditions in transportation networks at the right time (Munim et al. 2020; Shang, et al.2017; Yanget al. 2019).

The improvement of emergency logistics and humanitarian logistics in a disaster is a very important research issue. Lau et al. (in press) identified key factors for the successful implementation of emergency logistics systems in the context of China's COVID-19 pandemic. Besides, structural change in the logistics market before and after COVID-19 is an important topic of research.

The logistics industry is facing two opposite phenomena during the COVID-19 pandemic in terms of demand. On one hand, global freight flows are expected to decline due to the trade downturn. McKinsey (2020) estimates that ocean container traffic demand will decline by six percent to 20 percent in 2020 compared to 2019. On the other hand, the last-mile delivery market is growing rapidly, along with growth in online consumption. As consumers shifting their consumption patterns to non-face-toface ways due to concerns about the spread of the epidemics, e-commerce and parcel delivery businesses are growing simultaneously. The U.S. Department of Commerce reported that second-quarter 2020 e-commerce estimates increased by 44.5 percent over the second quarter of 2019, while total retail sales decreased 3.6 percent in the same period (USDOC 2020).

Analyzing GVC is a promising way to understand the ripple effect of the COVID-19 pandemic. There are existing trade databases that enable GVC analysis, including the World Input-Output Database (WIOD), the OECD Inter-Country InputOutput (ICIO) tables, and Asian Development Bank Multi-Regional Input-Output (ADB-MRIO) tables. While time-series data are available, the weakness is that they take several years to collect and release. For example, the OECD ICIO tables cover 65 economies and 36 industries for the years from 2005 to 2015 (OECD 2019).

These big-data capabilities of the trade, maritime, aviation and logistics industries will be utilized as important assets for analyzing the impact of accidents or disasters, and for further improving risk management capabilities to quickly identify and respond to causes.

\section{References}

Chung, H. M., Kwon, O. K., Han, O. S., Kim, H., 2020. Evolving network characteristics of the Asian international aviation market: A weighted network approach. Transport Policy 99, 299-313.

Golan, M. S., Jernegan, L. H., Linkov, I., 2020. Trends and applications of resilience analytics in supply chain modeling: Systematic literature review in the context of the COVID-19 pandemic. Environment Systems and Decisions 40, 222-243.

International Air Transport Association [IATA]., 2020. Recovery Delayed as International Travel Remains Locked Down. Available at https://www.iata.org/en/pressroom/pr/2020-07-28-02/

Ivanov, D., 2020. Predicting the impacts of epidemic outbreaks on global supply chains: A simulation-based analysis on the coronavirus outbreak (COVID-19/SARS-CoV-2) case. Transportation Research Part E: Logistics and Transportation Review 136, 101922.

Kim, S., Yoon, Y., 2019. On node criticality of the Northeast Asian air route network. Journal of Air Transport Management 80, 101693.

Loske, D., 2020. The impact of COVID-19 on transport volume and freight capacity dynamics: An empirical analysis in German food retail logistics. Transportation Research Interdisciplinary Perspectives 6, 100165.

McKibbin, W., Fernando, R., 2020. The global macroeconomic impacts of COVID-19: Seven scenarios. Asian Economic Papers. Availalbe at: https://doi.org/10.1162/asep_a_00796

McKinsey., 2020. Global freight flows after COVID-19: What's next? Available at https://www.mckinsey.com/industries/ travel-logistics-and-transport-infrastructure/our-insights/global-freight-flows-after-covid-19-whats-next

Munim, Z. H., Dushenko, M., Jimenez, V. J., Shakil, M. H., Imset, M., 2020. Big data and artificial intelligence in the maritime industry: A bibliometric review and future research directions. Maritime Policy \& Management 47, 577-597.

Organization for Economic Cooperation and Development [OECD], 2019. Guide to OECD’s Trade in Value Added (TiVA) Indicators, 2018 edition. Paris, France.

Organization for Economic Cooperation and Development [OECD], 2020. COVID-19 and Global Value Chains: Policy Options to Build More Resilient Production Networks. Available at http://www.oecd.org/coronavirus/policy-responses/covid-19and-global-value-chains-policy-options-to-build-more-resilient-production-networks-04934ef4/

Queiroz, M. M., Ivanov, D., Dolgui, A., Fosso Wamba, S., 2020. Impacts of epidemic outbreaks on supply chains: Mapping a research agenda amid the COVID-19 pandemic through a structured literature review. Annals of Operations Research. 
Available at: https://doi.org/10.1007/s10479-020-03685-7

Shang, Y., Dunson, D., Song, J. S., 2017. Exploiting big data in logistics risk assessment via bayesian nonparametrics. Operations Research 65, 1574-1588.

Sherman, E., 2020. 94\% of the Fortune 1000 are seeing Coronavirus Supply Chain Disruptions: Report. Fortune. Available at https://fortune.com/2020/02/21/fortune-1000-coronavirus-china-supply-chain-impact

Sun, X., Gollnick, V., Wandelt, S., 2017. Robustness analysis metrics for worldwide airport network: A comprehensive study. Chinese Journal of Aeronautics 30, 500-512.

US Department of Commerce [USDOC], 2020. The 2nd Quarter 2020 Retail E-Commerce Sales Report. Available at https://www.census.gov/retail/index.html

World Health Organization [WHO], 2020. Naming the Coronavirus Disease (COVID-19) and the Virus that causes It. Available at https://www.who.int/emergencies/diseases/novel-coronavirus-2019/technical-guidance/naming-the-coronavirus-disease(covid-2019)-and-the-virus-that-causes-it

World Trade Organization [WTO], 2020. Trade Falls Steeply in First Half of 2020. Available at https://www.wto.org/ english/news_e/pres20_e/pr858_e.htm

Yang, D., Wu, L., Wang, S., Jia, H., Li, K. X., 2019. How big data enriches maritime research: A critical review of Automatic Identification System (AIS) data applications. Transport Reviews 39, 755-773. 